Lepr Rev (1996) 67, 18-27

\title{
Leprosy in Myanmar, epidemiological and operational changes, 1958-92
}

\author{
TIN MYINT* \& MYO THET HTOON \\ Yangon, Myanmar
}

Accepted for publication 18 August 1995

Summary The registered caseload and prevalence of leprosy have declined in Myanmar from a peak of 86.2 per 10,000 population (95\% CI $85.43-86.97)$ in $1973-77$ to $26 \cdot 82(95 \%$ CI $18 \cdot 46-35 \cdot 18)$ in $1988-92$. The new case detection rates have also declined from $7 \cdot 41$ per $10,000(95 \%$ CI $6 \cdot 3-8 \cdot 52)$ in $1968-72$ to 1.96 $(95 \%$ CI $1.43-2.52)$ in $1988-92$. The increase in the multibacillary proportion of new cases from $11 \cdot 85 \%(95 \%$ CI $11 \cdot 84-11 \cdot 86)$ in $1968-72$ to $40 \cdot 54 \%(95 \%$ CI $37 \cdot 2-43 \cdot 88$ ) in $1988-92$ and the decline in proportion of new cases under 14 years of age from $26 \cdot 81 \%(95 \%$ CI $26 \cdot 8-26 \cdot 82)$ in $1968-72$ to $11 \cdot 22 \%(95 \%$ CI $10 \cdot 92-$ $11 \cdot 52$ ), coupled with the finding of declining detection rates among school children and in mass village surveys could mean that the incidence of leprosy may be declining.

\section{Introduction}

Leprosy is a major health problem in Myanmar and throughout the centuries many social problems were created as a result of local communities' attitudes and actions in dealing with this disease. Before the discovery of chemotherapy for leprosy in Myanmar, as in most countries in the world, leprosy patients were isolated as part of the policy for control of leprosy. With the introduction of dapsone for the treatment of leprosy during the mid 1950s, the approach toward leprosy became more humane.

Myanmar started its leprosy control programme in 1952 with the establishment of special centres where leprosy patients were admitted for treatment and provided with food and housing. Dapsone was first used on a mass scale for leprosy control in 1958, when a domiciliary treatment programme was started in areas with a high leprosy prevalence. Nationwide coverage of domiciliary treatment with dapsone was achieved in 1969. From 1958 to 1969 , as domiciliary treatment became more common, fewer and fewer patients were accepted into the special treatment centres and patients were

\footnotetext{
${ }^{*}$ Correspondence: Dr Myo Thet Htoon, 653 (B) Pyay Road, Myakantha Lane, University P.O. 11041, Yangon, Myanmar (Burma) 
encouraged to take treatment at home. This approach made treatment widely available to a large number of patients without disrupting their livelihood and family ties. Treatment of leprosy patients without isolation raised community awareness of the disease and forced development of strategies for dealing with leprosy as a public health problem. Depending on the endemicity of the disease and outlook of the community, these strategies ranged from total isolation and neglect to full acceptance of leprosy patients as active members of the community. As the leprosy control programme matured, and the treatment proved effective, community attitudes towards leprosy patients slowly changed and demands for isolation and acts of discrimination became less frequent.

In 1978, a major operational change was made in the leprosy control programme in Myanmar and involved integration of certain control activities into the primary health care programme of the basic health service. Specifically, case-finding and treatment activities were taken over by the basic health service. As a result, basic health service personnel became more aware of the needs of leprosy patients. However in the beginning, the integration was fraught with problems, including a reduced quality of care, increased noncompliance of patients and outright refusal by some of the basic health staff to treat leprosy patients. A strong political commitment to the integration and continuous training of the basic health service personnel have to a great extent alleviated these problems.

From 1958 to 1984, dapsone monotherapy was the standard regimen for treatment of leprosy. In 1984, a policy of administering rifampicin to lepromatous and borderline cases was implemented with the aim of reducing the bacillary load in these patients and thereby interrupting the chain of transmission. Supervised treatment with a monthly single dose of $1200 \mathrm{mg}$ rifampicin for six consecutive months, together with daily $100 \mathrm{mg}$ dose of dapsone, unsupervised, was followed by a $1500 \mathrm{mg}$ dose of rifampicin once a year. This became the standard of treatment for lepromatous and borderline patients until 1987 in the high prevalence areas of Mandalay, Sagaing, Magway, Bago, Yangon, Ayeyarwady Divisions and the Shan State.

Another major change in the leprosy control programme occurred in 1988 when the WHO recommended multidrug therapy (MDT) regimen was first introduced in the six leprosy hyperendemic regions (Mandalay, Sagaing, Magway, Bago, Yangon and Ayeyarwady Divisions) which account for $90 \%$ of the registered cases in Myanmar. MDT was initially provided on a domiciliary treatment basis by the leprosy control programme and later MDT treatment was fully integrated into the primary health care programme in 1991.

This study was conducted to evaluate the epidemiologic outcome of operational changes that occurred in the leprosy control programme of Myanmar during the period 1958-92.

\section{Method}

This study represents a retrospective analysis of data on the occurrence of leprosy from the following sources: Statistical Assessment on the Prevalence of Leprosy in Burma, 1971; Annual Returns to the Health Information Service, 1958 to 1974; Health Report of the Direector of Health services, August 1971; Health Information Report of the Health 
Information Service, 1975; and the Annual Reports of the Leprosy Control Programme, 1984 to 1992.

To compare types of reported leprosy cases over time, the present World Health Organization (WHO) classification of leprosy into paucibacillary (PB) and multibacillary (MB) forms was used. ${ }^{1}$ Cases classified according to the Madrid system as indeterminate, tuberculoid and lepromatous in the routine reporting forms for leprosy during the period 1958-88 were reclassified by grouping indeterminate and tuberculoid into the PB category and the lepromatous (including borderline cases) into the MB category. Slit-skin smears are currently performed by staff of the leprosy control programme as part of their supervision of basic health services leprosy control work. The quality of the smear examinations has been more or less the same throughout the years but smear examinations are less often performed because of a reduction in supervision activities.

During the period under study (1958-92), the leprosy control programme used contact surveillance, examination of school children and mass surveys for active casefindings. A contact is defined as an individual living under the same roof with a leprosy patient who is taking treatment. Mass surveys were primarily conducted in villages, with priority given to villages with a high lepromatous proportion among the registered cases and villages not surveyed during the previous 5 years. School surveys were conducted mainly in primary and secondary schools.

In 1974 indeterminate and tuberculoid cases began to be released for control (RFC). With the introduction of MDT in 1988, MB cases were discharged from the register after completion of the WHO recommended treatment regimen. Fixed duration treatment was introduced in 1991. MB cases were regarded as cured and were discharged after receiving 24 doses within a period of 36 consecutive months. PB cases were discharged after receiving 6 doses within 9 consecutive months. Prior to the introduction of MDT, borderline and lepromatous cases were treated with dapsone monotherapy for life.

Relapse is defined as appearance of new lesion(s) in a patient who has been discharged (released from treatment). The diagnosis of relapse is based mainly on clinical grounds. Where laboratory services are reliable, transition from negative at the time of discharge to positive skin smear has been taken as a sign of relapse.

Yearly data from 1958 to 1992 were grouped into 5-year intervals and average values were calculated for prevalence, MB proportion and proportion under 14 years old. The last 5-year interval of 1988 to 1992 was the period when MDT was introduced in the country. Mantel-Haenzel tests for trend were performed and the $95 \%$ confidence intervals were calculated for the registered prevalence and new case detection for each time interval.

\section{Results}

Table 1 shows the registered cases and prevalence of leprosy in Myanmar for 5-year intervals from 1958-62 to 1988-92. The total number of registered cases increased during each consecutive time period until 1973-77 when the total number was 261,000 and then started to decline. With the start of the MDT programme in 1988, the registered caseload dropped markedly to 107,944 cases in 1988-92. The registered prevalence rate also followed a similar pattern. From 31.96 per 10,000 population (95\% CI $25-39)$ in 
Table 1. Registered prevalence (per 10,000), registered MB proportion (\%) and registered under 14 years proportion $(\%)$

\begin{tabular}{lcccc}
\hline Year & $\begin{array}{c}\text { Reg:* } \\
\text { cases }\end{array}$ & $\begin{array}{c}\text { Reg: }^{*} \\
\text { Prev: }(95 \% \mathrm{CI})\end{array}$ & $\begin{array}{c}\text { Reg: MB proportion } \\
(95 \% \mathrm{CI})\end{array}$ & $\begin{array}{c}\text { Reg: }<14 \mathrm{yr} \\
\text { prop: }(95 \% \mathrm{CI})\end{array}$ \\
\hline $1958-1962$ & 69,949 & $31 \cdot 96$ & $43 \cdot 26$ & $23 \cdot 17$ \\
& & $(24 \cdot 71-39 \cdot 21)$ & $(38 \cdot 2-48 \cdot 32)$ & $(22 \cdot 91-23 \cdot 43)$ \\
$1963-1967$ & 157,236 & $64 \cdot 7$ & $29 \cdot 27$ & $23 \cdot 12$ \\
& & $(59 \cdot 49-69 \cdot 91)$ & $(27 \cdot 08-31 \cdot 46)$ & $(20 \cdot 95-25 \cdot 29)$ \\
$1968-1972$ & 225,445 & $83 \cdot 24$ & $24 \cdot 54$ & $16 \cdot 44$ \\
& & $(80 \cdot 18-86 \cdot 3)$ & $(23 \cdot 51-25 \cdot 57)$ & $(14 \cdot 95-17 \cdot 93)$ \\
$1973-1977$ & 261,606 & $86 \cdot 2$ & $22 \cdot 26$ & $10 \cdot 9$ \\
& & $(85 \cdot 43-86 \cdot 97)$ & $(22 \cdot 1-22 \cdot 42)$ & $(9 \cdot 75-12 \cdot 05)$ \\
$1978-1982$ & 257,470 & $76 \cdot 68$ & $22 \cdot 9$ & $6 \cdot 48$ \\
& & $(73 \cdot 92-79 \cdot 44)$ & $(22 \cdot 41-23 \cdot 39)$ & $(5 \cdot 71-7 \cdot 25)$ \\
$1983-1987$ & 231,871 & $62 \cdot 96$ & $24 \cdot 79$ & $5 \cdot 28$ \\
$1988-1992$ & 107,944 & $(57 \cdot 7-68 \cdot 22)$ & $(23 \cdot 57-26 \cdot 01)$ & $(5 \cdot 04-5 \cdot 52)$ \\
& & $(18 \cdot 42-35 \cdot 18)$ & $(39 \cdot 55$ & $4 \cdot 17$ \\
& & & & $(3 \cdot 91-4 \cdot 43)$ \\
\hline
\end{tabular}

${ }^{*}$ Average registered cases and prevalence for the time interval.

$1958-62$, it increased until it reached a peak of 86.2 per 10,000 population $(95 \%$ CI $85-$ 87 ) in 1973-77. It then declined slowly during $1978-82$ to $1983-87$ and with the introduction of MDT, declined further to 26.82 per 10,000 population $(95 \%$ CI $18-$ 35) during 1988-92.

At the start of the control programme in 1958-62, the MB proportion among registered cases was $43 \cdot 26 \%(95 \%$ CI $38-48)$ and the proportion of cases under 14 years old was $23 \cdot 17 \%(95 \%$ CI $22 \cdot 9-23 \cdot 4)$. As the programme matured, the MB proportion among registered cases levelled off at approximately $22 \%$ during $1973-77$ to $1978-82$. The MB proportion increased again during the period $1988-92$ to $46.55 \%$ (95\% CI 40 53). The proportion of registered cases under 14 years old consistently declined, reaching a level of $4 \cdot 17 \%(95 \%$ CI $3 \cdot 9-4 \cdot 4)$ in $1988-92$.

Table 2. Total new cases, new case detection rate (per 10,000), new case MB proportion and proportion of new cases under 14 years

\begin{tabular}{|c|c|c|c|c|}
\hline Year & $\begin{array}{l}\text { New } \\
\text { cases }\end{array}$ & $\begin{array}{l}\text { New case } \\
\text { detection } \\
(95 \% \text { CI })\end{array}$ & $\begin{array}{c}\text { New case MB } \\
\text { proportion } \\
(95 \% \mathrm{CI})\end{array}$ & $\begin{array}{l}\text { New cases under } \\
14 \text { yr proportion } \\
(95 \% \mathrm{CI})\end{array}$ \\
\hline $1968-1972$ & 61,350 & $\begin{array}{l}7 \cdot 41 \\
(6 \cdot 30-8 \cdot 52)\end{array}$ & $\begin{array}{l}11 \cdot 85 \\
(11 \cdot 84-11 \cdot 86)\end{array}$ & $\begin{array}{l}26 \cdot 81 \\
(26 \cdot 8-26 \cdot 82)\end{array}$ \\
\hline $1973-1977$ & 54,660 & $\begin{array}{l}3 \cdot 61 \\
(3 \cdot 27-3 \cdot 94)\end{array}$ & $\begin{array}{l}15 \cdot 37 \\
(12 \cdot 29-18 \cdot 45)\end{array}$ & $\begin{array}{l}21 \cdot 63 \\
(18.97-24 \cdot 29)\end{array}$ \\
\hline $1978-1982$ & 49,603 & $\begin{array}{l}2 \cdot 96 \\
(2 \cdot 58-3 \cdot 35)\end{array}$ & $\begin{array}{l}19 \cdot 69 \\
(17 \cdot 53-21 \cdot 85)\end{array}$ & $\begin{array}{l}18 \cdot 82 \\
(18 \cdot 02-19 \cdot 62)\end{array}$ \\
\hline $1983-1987$ & 37,918 & $\begin{array}{l}2.07 \\
(1.52-2.62)\end{array}$ & $\begin{array}{l}34.33 \\
(32 \cdot 57-36 \cdot 09)\end{array}$ & $\begin{array}{l}14 \cdot 96 \\
(13 \cdot 58-16 \cdot 34)\end{array}$ \\
\hline $1988-1992$ & 38,618 & $\begin{array}{l}1.96 \\
(1.43-2.52)\end{array}$ & $\begin{array}{l}40 \cdot 54 \\
(37 \cdot 2-43 \cdot 88)\end{array}$ & $\begin{array}{l}11 \cdot 22 \\
(10 \cdot 92-11 \cdot 52)\end{array}$ \\
\hline
\end{tabular}


Table 2 shows new case detection rates, new case MB proportions and the proportion of new cases under 14 years old. Rates for earlier years (1958-62 and 1963-77) were not available. The total number of new cases detected over the period declined from 61,350 in $1968-72$ to 38,618 in $1988-92$. New case detection rates also declined consistently from a high of $7 \cdot 41$ per 10,000 population (95\% CI 6-9) in $1968-72$ to 1.9 per 10,000 population $(95 \%$ CI $1-3)$ in 1988-92. This trend was significant at $p<0 \cdot 003$. During the same period, the MB proportion among new cases increased from $11 \cdot 85 \%(95 \% \mathrm{CI}$ $11 \cdot 8-11 \cdot 9)$ in $1968-72$ to $40 \cdot 54 \%(95 \%$ CI $37-44)$ in $1988-92$ and the proportion of new cases under 14 years old decreased from $26 \cdot 81 \%(95 \%$ CI $26 \cdot 80-26 \cdot 82)$ in $1968-72$ to $11 \cdot 22 \%(95 \%$ CI $10 \cdot 9-11 \cdot 5)$ in $1988-92$.

Table 3 shows the detection rates for contract surveillance (1963-67 to 1988-92), examinations of school children (1973-77 to 1988-92) and mass village surveys (197377 to 1988-92). At the start of the programme in 1963-67, contact detection rates were high, 9.09 per 1000 contacts examined (95\% CI 7-11). This rate declined to a low of 1.86 per $1000(95 \%$ CI $1 \cdot 6-2 \cdot 1)$ in $1978-82$ and again increased significantly $(p<0.003)$ to 3.48 per $1000(95 \%$ CI $2-5)$ in $1988-92$.

The detection rate for school children declined significantly $(p<0.003)$ from a high of 0.87 per 1000 school children examined (95\% CI $0 \cdot 7-1)$ in $1973-77$ to 0.31 per 1000 (95\% CI $0 \cdot 3-0 \cdot 4)$ in 1988-92. The decline was consistent throughout the observation period. The detection rate from mass surveys was 5.02 per 1000 population examined $(95 \%$ CI $3-7)$ in $1973-77$ and showed a significant decline $(p<0.003)$ to 1.73 per 1000 $(95 \%$ CI $1 \cdot 2-2 \cdot 3)$ in $1988-92$.

Table 4 shows average numbers and proportion of new cases detected per year through passive case finding methods during each time period from 1973-77 to 1988-92. Data on earlier years were not available. Average numbers of new cases detected through passive case-finding methods declined from 7489 in $1973-77$ to 5711 in 1988-92. At the same time, the proportion of new cases detected through passive case-findings increased significantly from $68.43 \%(95 \%$ CI $64 \cdot 27-72 \cdot 59)$ in $1973-77$ to

Table 3. Contact detection rate, school detection rate, mass survey detection rate

\begin{tabular}{|c|c|c|c|c|c|c|}
\hline \multirow[b]{2}{*}{ Year } & \multicolumn{2}{|c|}{ Contact exam: } & \multicolumn{2}{|c|}{ School exam: } & \multicolumn{2}{|c|}{ Mass survey } \\
\hline & No: & $\begin{array}{c}\text { Rate }^{*} \\
(95 \% \mathrm{CI})\end{array}$ & No: & $\begin{array}{c}\text { Rate }^{*} \\
(95 \% \text { CI })\end{array}$ & No: & $\begin{array}{c}\text { Rate }^{*} \\
(95 \% \text { CI })\end{array}$ \\
\hline $1963-1967$ & $1,524,727$ & $\begin{array}{l}9 \cdot 09 \\
(6 \cdot 82-11 \cdot 36)\end{array}$ & - & - & - & - \\
\hline $1968-1972$ & $2,232,576$ & $\begin{array}{l}6 \cdot 22 \\
(5 \cdot 38-7 \cdot 06)\end{array}$ & - & - & - & - \\
\hline $1973-1977$ & $2,119,346$ & $\begin{array}{l}4 \cdot 07 \\
(2 \cdot 77-5 \cdot 37)\end{array}$ & $3,738,289$ & $\begin{array}{l}0.87 \\
(0.72-1.02)\end{array}$ & $1,149,802$ & $\begin{array}{l}5 \cdot 02 \\
(3 \cdot 26-6 \cdot 78)\end{array}$ \\
\hline $1978-1982$ & $1,960,034$ & $\begin{array}{l}1.86 \\
(1.63-2.09)\end{array}$ & $2,881,626$ & $\begin{array}{l}0.75 \\
(0.59-0.91)\end{array}$ & $2,523,269$ & $\begin{array}{l}3.77 \\
(3.05-4.49)\end{array}$ \\
\hline $1983-1987$ & $1,112,675$ & $\begin{array}{l}2.54 \\
(1.97-3 \cdot 11)\end{array}$ & $1,886,923$ & $\begin{array}{l}0.46 \\
(0.39-0.53)\end{array}$ & $1,598,644$ & $\begin{array}{l}1.8 \\
(1.63-1.97)\end{array}$ \\
\hline $1988-1992$ & 857,830 & $\begin{array}{l}3 \cdot 48 \\
(2 \cdot 39-4 \cdot 58)\end{array}$ & $2,369,652$ & $\begin{array}{l}0.31 \\
(0.26-0.36)\end{array}$ & $3,063,455$ & $\begin{array}{l}1.73 \\
(1.20-2 \cdot 26)\end{array}$ \\
\hline
\end{tabular}


Table 4. New cases detected through passive methods and passive case detection proportion

\begin{tabular}{lccc}
\hline Year & $\begin{array}{c}\text { Passively detected } \\
\text { cases }\end{array}$ & $\begin{array}{c}\text { Average new } \\
\text { cases/year (SD) }\end{array}$ & $\begin{array}{c}\text { Passive detection } \\
\text { proportion* }\end{array}$ \\
\hline $1973-1977$ & 37,434 & $7487(953 \cdot 75)$ & $68 \cdot 43(64 \cdot 27-72 \cdot 59)$ \\
$1978-1982$ & 34,498 & $6001(693 \cdot 69)$ & $69 \cdot 71(68 \cdot 19-71 \cdot 21)$ \\
$1983-1987$ & 31,409 & $6282(2149 \cdot 7)$ & $81 \cdot 7(77 \cdot 21-86 \cdot 19)$ \\
$1988-1992$ & 28,556 & $5711(1305 \cdot 67)$ & $76 \cdot 82(69 \cdot 16-84 \cdot 48)$ \\
\hline
\end{tabular}

* Average for the time interval.

$81 \cdot 7 \%(95 \%$ CI $77 \cdot 21-86 \cdot 19)$ in $1982-87$. The difference in the proportions in $1973-77$ and 1988-92 was not significant.

During the period from 1958 to 1987 , a total of 61,587 cases treated with dapsone monotherapy were discharged from the register (Table 5). Since the introduction of MDT in 1988, a total of 96,307 leprosy patients were discharged by December 1992. The MDT coverage among patients registered in 1992 was $55 \cdot 17 \%$ and the cumulative MDT coverage (proportion of all registered patients receiving MDT during 1988 to 1992) was $83 \cdot 28 \%$.

Table 6 gives the total number of relapse cases found each year, which were cases detected mainly through self-reporting. Relapses reported among PB cases also includes those treated with dapsone monotherapy in the past, since the routine reporting forms do not show them separately. The absolute numbers show that the relapses among $\mathrm{MB}$ cases were more common than among PB cases. Rates were not calculated for each year because the total number of discharges and the relapse cases were from different source populations.

\section{Discussion}

The data analysed in this study were routinely collected for monitoring leprosy control activities in Myanmar. These data are best interpreted in the context of operational changes in the leprosy control programme that occurred during the study period.

The registered number of leprosy cases increased yearly until 1977, a trend that may

Table 5. Total number of leprosy cases discharged from treatment with dapsone monotherapy and MDT and treatment coverage

\begin{tabular}{lccc}
\hline Treatment regimen & $\begin{array}{c}\text { Number } \\
\text { discharged }\end{array}$ & $\begin{array}{c}\text { Current } \\
\text { coverage (\%) }\end{array}$ & $\begin{array}{c}\text { Cumulative } \\
\text { coverage (\%) }\end{array}$ \\
\hline Dapsone (1958-87) & 61,587 & - & -17 \\
MDT (1988-92) & 96,307 & $55 \cdot 17$ & $83 \cdot 28^{*}$ \\
\hline
\end{tabular}

\footnotetext{
${ }^{*}$ Based on 1992 data.
} 
Table 6. Total relapse cases detected each year and number of cases discharged under MDT

\begin{tabular}{|c|c|c|c|c|c|c|}
\hline \multirow[b]{2}{*}{ Year } & \multicolumn{3}{|c|}{ No: of relapse } & \multicolumn{3}{|c|}{ No: of discharges under MDT } \\
\hline & PB & MB & Total & PB & $\mathrm{MB}$ & Total \\
\hline 1989 & 70 & 26 & 96 & 23,165 & 1978 & 25,143 \\
\hline 1990 & 48 & 66 & 114 & 10,504 & 12,521 & 23,025 \\
\hline 1991 & 8 & 42 & 50 & 6472 & 12,631 & 19,103 \\
\hline 1992 & 23 & 72 & 95 & 21,611 & 3027 & 24,638 \\
\hline Total & 149 & 206 & 355 & 61,752 & 30,157 & 91,909 \\
\hline
\end{tabular}

be attributable to the intensive case-finding activities that were carried out by the vertical leprosy control programme (Table 3). At the same time, cases accumulated on the register because of the strict criteria for release from control (RFC) that was used during that period. The decline observed after 1977 is likely to be attributable to an increase in the number of cases being discharged from the register with the introduction of more flexible criteria for release from control $1978^{2}$ in addition to a decline in the total number of new cases detected during each period (Table 2). This decline in new cases could have been due to an overall decline in the incidence but also may have resulted from the change in the leprosy control programme in the late seventies and early eighties from vertical programme to an integrated programme. During the transition period in which case-finding activities were transferred to the basic health services, the number of new cases declined perhaps because of inexperience in leprosy diagnosis on the part of the basic health service staff coupled with reluctance of patients to seek treatment from a different type of provider. The smaller decline observed in the registered prevalence from 1968 to 1982 compared with the dramatic decline of registered prevalence $(53 \%)$ between 1983 and 1992 might be explained by the fact that the registers were updated in 1987 and MDT was introduced in 1988. The shorter treatment duration required with MDT compared with dapsone monotherapy enabled the control programme to release a large number of cases $(96,307)$ from the register during this time period.

The high MB proportion among the registered cases at the start of the control programme stabilized at around 22\% and remained at this level from 1973 to 1982, even though some PB cases were discharged during the period. A similar trend has been reported from other southern Asian countries (5-20\%). ${ }^{3}$ The significant increase in the MB proportion among registered cases during the period 1988-92 is a result of implementing the MDT regimen, in which longer duration of treatment is required for $\mathrm{MB}$ cases as compared with $\mathrm{PB}$ cases. The increase in the MB proportion among the registered cases is also due in part to the increase in the MB proportion of new cases detected each year (Table 2). The effects of changes made in classification of leprosy cases from intermediate, tuberculoid and lepromatous to $\mathrm{PB}$ and $\mathrm{MB}$, as well as modifications made during the past years in classifying PB and MB, could have brought about higher $\mathrm{MB}$ proportion among the registered cases also. It is difficult to know how much of this increase observed in the MB proportion through-out the years is due to the true change in the epidemiological pattern of the disease.

The proportion of registered cases under 14 years of age declined continuously 
during the study period, and might be attributable to the reduction of transmission among children. This interpretation is supported by a consistent decline of the school detection rates (Table 3 ) as well as of the proportion of new cases under 14 years old (Table 2).

During the period 1988-92 while the new case detection rate decreased, the MB proportion of new cases increased and at the same time the proportion of new cases under 14 years of age declined (Table 2). These changes could be due to a decline in the incidence of leprosy in the country. ${ }^{1,3,4}$ A similar pattern was found in Thailand ${ }^{5}$ and Malawi. ${ }^{6}$ A possible alternative explanation for an increase in the MB proportion of new cases is that increased reliance on passive case-finding could have led to an increased $\mathrm{MB}$ proportion, since cases detected passively tend to be older and more likely to have MB leprosy. The proportion of passively detected cases has increased significantly from 1973 to 1987 with the exception of the last period 1988-92 (Table 4). Comparison of the two periods, 1973-77 and 1988-92, shows that the proportion of new cases detected through passive methods has not changed significantly, whereas the MB proportion of new cases has changed significantly from $15 \cdot 37 \%$ (95\% CI $12-18)$ to $40 \cdot 54 \%$ (95\% CI $37-44)$. Considering that the increase in the MB proportion of new cases and the decline in proportion of new cases under 14 years old could not have been due solely to increases in the proportion of new cases detected through passive means, and the additional finding of declining detection rates among school children and mass surveys could mean that the overall incidence of leprosy is declining in the country. This interpretation is based on the assumption that the quality of screening conducted in schools and villages has been constant throughout the study period.

During the period studied, incidence may have fallen because of a reduction in transmission of infection as a result of chemotherapy (dapsone early on and MDT later) or alternatively, because of the effect of increasing coverage of BCG achieved by the Expanded Programme for Immunization since the early eighties, improvement in living standards (and consequently better personal hygiene), or a combination of these factors. Data showing the specific effects of chemotherapy or the improvement in living standards on the transmission of Mycobacterium leprae is unavailable for Myanmar. Several studies have shown that BCG provides varying levels of protection against leprosy (20 to $80 \%)^{3,7-10}$ In a recent case-control study conducted in Myanmar by Bertolli, ${ }^{11}$ a single dose of BCG was found to give an overall protection of $55 \%(95 \% \mathrm{CI}$ 21-74) and with protection up to $87 \%$ (95\% CI 69-95) with administration of 3 doses.

In an earlier study which was conducted in Myanmar during 1962 to 1972, the case detection rates in 12 project areas of Central Myanmar were found to be decreasing for all types of leprosy and for all ages. ${ }^{12}$ The decline in the new case detection rate prior to the introduction of rifampicin (1984) and MDT (1988) in Myanmar was similar to that found in Thailand, ${ }^{5}$ Malawi $^{6}$ and French Polynesia. ${ }^{13}$

Information on the proportion with disability grade two among new cases can be used to study how well new case detection reflects incidence. However, this information was not available at the national level because it was not collected routinely. But in a study of 320 new cases in Hmawbi Township (Myanmar) from 1964 to 1974, the overall grade two disability rate among new cases was $26 \cdot 88 \%$. In this same study, grade two disability among new cases in contacts of leprosy patients was $15 \cdot 25 \%, 12.9 \%$ among new cases found during school surveys, 33.9\% among cases detected by mass surveys and $32.5 \%$ for cases detected passively. ${ }^{14}$ These figures show that there was a 
considerable time lag between onset of disease and detection even during the time when leprosy control was a verticle programme.

The only prospective data on leprosy incidence comes from the BCG trial conducted in Central Myanmar ${ }^{7}$ between 1964 and 1978, in which incidence among the vaccinated and control groups was 8.6 and 12.6 per 100,000 per year, respectively. The national data for new case detection at that time was $7 \cdot 41$ per 10,000 during 1968-72 and 3.61 during 1973-77. The new case detection rate in Central Myanmar (which includes the BCG trial area) for 1972 was 8 per 10,000 population. ${ }^{12}$ The discrepancy found between the prospective data and survey detection rates shows that new case detection rates do not approximate incidence very well. Routine collection of the proportion of new cases with disability is essential for future evaluation of the case detection rates.

A total of 61,587 cases were released from control during the 30 years of dapsone monotherapy (1958-87) and 96,307 were discharged in just 5 years after the introduction of MDT (1988-92). This dramatic contrast highlights the immediate benefit of MDT, and provides incentive to increase MDT coverage beyond the current level of $55 \cdot 17 \%$ and expand into the uncovered regions by integrating into existing primary health care systems operating in these areas of the country. The cumulative MDT coverage attained for the whole country was $83 \cdot 28 \%$ (1992), and this coverage was achieved mainly through integration of MDT into the primary health care programme.

The number of relapses found each year are low. The number of relapses found during the four-year period from 1989 to 1992 was 355. Under reporting or most probably, a delay in reporting of relapse cases could be occurring because relapses are detected only through passive means by patient self-report. At the same time, the tendency to over diagnose a case of relapse with the use of a simple clinical criteria especially in the field is also possible, and these two factors could be cancelling each other out in estimating relapses. Taking into consideration control measures being integrated into the primary health care programme and the low relapse rates with MDT observed in other programmes by $\mathrm{WHO},{ }^{15}$ active surveillance of cases discharged (cured) after treatment is not recommended for screening of relapse in Myanmar.

The epidemiological pattern of leprosy in Myanmar has changed over time. With the expansion of MDT coverage in the coming years, the trend of decline observed in the registered prevalence is expected to continue. Increasing the coverage of MDT is expected to facilitate interrupting the chain of transmission and contribute greatly to progress in eliminating leprosy in Myanmar.

\section{Acknowledgment}

The authors would like to thank the National Leprosy Control Programme for providing the necessary information. We would also like to thank Dr J. Bertolli for her help and comments in writing this article.

\section{References}

1 World Health Organization Technical Report Series, 768, 1988. WHO Expert Committee on Leprosy: Sixth Report. Geneva. 
${ }^{2}$ Htoon MT. Relapse rate in leprosy patients relased from control in Minbu Leprosy Control Project, Myanmar 1978-1981. Myanmar Med J. 1991; 36: 1-4. 46-58

3 World Health Organization Technical Report Series, 716, 1985. Epidemiology of Leprosy in Relation to Control: Report of a WHO Study Group. Geneva.

${ }^{4}$ Irgens LM. Leprosy in Norway. An epidemiological study based on a national patient registry. Lepr Rev 1980; 51: (Supp. 1) i-xi, 1-130.

${ }^{5}$ Pirayavaraporn C, Peerapakorn S. The measurement of the epidemiological impact of multi drug therapy. Lepr Rev, 1992; 63: (Suppl) 84S-92S.

${ }^{6}$ Boerrigter G, Ponnighaus JM. Does the introduction of WHO-MDT influence trends in the incidence of leprosy?-the Malawian experience. Lepr Rev, 1993; 64: 227-35.

${ }^{7}$ Kyaw Lwin, Sundaresan T, Mg Mg Gyi, Bechelli LM, Tamondong C, Gallego Garbajosa P, Sansarricq H, Noorden SK. BCG vaccination of children against leprosy: fourteen years findings of the trail in Burma. Bull Wld Hlth Org, 1985; 63: 1069-78.

${ }^{8}$ Convit J, Smith PG, Zuniga M, Sampson C, Ulrich M, Plata JA, Silva J, Molina J, Salgado A. BCG vaccination protects against leprosy in Venezuela: A case-control study. Int J Lepr, 1993; 61: 185-99.

9 Baker DM, Nguyen Van Tam JS, Smith SJ. Protective efficacy of BCG vaccine against leprosy in Southern Malawi. Epidemiol Infects, 1993; 111: 21-5.

${ }^{10}$ Rodrigues MLO, Silva SA, Neto JCA, Andrade ALSS, Martelli CMT, Zicker F. Protective effect of intradermal BCG against Leprosy: A case-control study in Central Brazil. Int J Lepr, 1992; 60: 335-9.

11 Bertolli J. A case-control study of the effectiveness of BCG vaccine for preventing leprosy in Yangon, Myanmar, (PhD Dissertation, University of California at Los Angeles, 1994).

12 Kyaw Lwin, Zuiderhoek B. Case detection rates for Central Burma (1962-1972). Int J Lepr, 1975; 43: $125-8$.

13 Cartel JL, Spiegel A, Nguyen Ngoc, Monlia-Pelat JP, Martin PMV, Grosset JH. Leprosy in French Polynesia. The possible impact of multi drug therapy on epidemiological trends. Lepr Rev, 1992; 63: 223-30.

${ }^{14}$ Myint T, Tin K, Htoon MT, Win M. Effectiveness of the different modes of case detection in Hmawbi Leprosy Control Project, 1964-1974. Myanmar Med J, 1991; 30: 39-45.

15 Risk of relapse in leprosy. Leprosy Unit, Division of Control of Tropical Diseases. Geneva, World Health Orgainzation, 1994. WHO/CTD/LEP/94.1. 